\title{
Diabetes Related Complications Severity Analysis Based on Hybrid Fuzzy Multi-Criteria Decision Making Approaches
}

\author{
Morteza Ebrahimi $^{*}{ }^{1}$, Khatereh Ahmadi $^{1}$ (i) \\ 1- Faculty of New Sciences and Technologies, University of Tehran, Tehran, Iran
}

\begin{abstract}
Introduction: Type 2 diabetes mellitus is a significant global public health problem affecting more than 285 million people worldwide. Evidence suggests that lifestyle and other non-pharmacological interventions can delay and even prevent the development of disease and its complications. This disease should be effectively controlled because of its complications including cardiovascular diseases, neuropathy, retinopathy, kidney diseases and etc.

Material and Methods: In this research two fuzzy Multi-Criteria Decision Making (MCDM) approaches including fuzzy TOPSIS and fuzzy Grey Relational Analysis (GRA) methods are used to decide the significance of Article History Received: 2017-05-07 Accepted: 2017-06-10 Published: 2017-06-15 each diabetes complications due to its main risk factors.

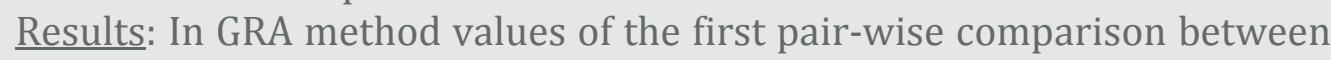
criterions were defined in interval-valued fuzzy numbers, this puts more accuracy on the problem and the final ranking obtained from this method was a little different in sorting and weights of alternatives compared to fuzzy TOPSIS method.

Conclusion: It is a new view point of fuzzy MCDM methods to be used for analysis of complications due to a specific disease.

\section{Keywords \\ Diabetes \\ Complications \\ Fuzzy decision making \\ Risk factors \\ $A H P$ \\ TOPSIS}

GRA




\section{INTRODUCTION}

Diabetes mellitus is one of the most common chronic diseases worldwide and is associated with an increased morbidity and mortality. Diabetes is characterized by chronic hyperglycemia and alterations of cellular homeostasis which lead to diffuse vascular damage [1]. Several risk factors are implicated in the pathogenesis of diabetic complications and they can be either modifiable (Glycemic control, hypertension, dyslipidemia, diet, smoking) or non-modifiable (diabetes duration, age at onset, puberty, genes).

In type 1 diabetes, the body's immune system destroys the cells that release insulin, eventually eliminating insulin production from the body. Without insulin, cells cannot absorb sugar (glucose), which they need to produce energy.

Type 2 diabetes accounts for the vast majority of people who have diabetes-90 to 95 out of 100 people. In type 2 diabetes, the body isn't able to use insulin in the right way. This is called insulin resistance. As type 2 diabetes gets worse, the pancreas may make less and less insulin. This is called insulin deficiency [2].

There are many risk factors for developing type 2 diabetes including: high cholesterol, high blood pressure, obesity, physical inactivity, smoking, family history, age and gender. These factors may lead to type 2 diabetes or may exacerbate the effects and complications in diabetic people. For example obesity, which is now prevalent in most developed countries, is a major risk factor which can develop to diabetes or exacerbate the complications like cardiovascular diseases in diabetics.

In [2] all types of diabetes including type 2 diabetes which is considered in this paper are discussed. The risk factors and their importance on diabetes and diabetes related complications with their importance are generally described. These issues are also discussed in many other healthcare websites [믈 or specifically diabetes associations like American Diabetes Association [7], National Diabetes Education Program [8], Joslin Diabetes Center [9], American Heart Association [10] and etc.

In this paper, the information from resources mentioned above, and also the expert's opinion is necessary for filling some matrices. However this available information is defined in linguistic terms such as most important, major importance, more likely, less likely and etc. these linguistic terms should be changed with mathematical methods to be useable in all numerical operations. In this paper fuzzy methods are effectively utilized for this problem.

The problem of diabetes complications severity analysis is looked as a decision problem in this research and a hierarchical structure is made based on diabetes risk factors and its complications. The final solution of this multi-criteria problem is the ranking of diabetes complications based on their importance and significance due to the probability of catching between diabetic people. There is some level of uncertainty in the importance of risk factors and severity of complications, because these issues sometimes depend on individual or time and place circumstances. To determine the pair-wise comparison between main criterions or risk factors the expert opinion or statistical data is needed. Sometimes it is not possible to determine the exact values in the pair-wise comparison matrix due to multiple reasons. In the scope of this research there is some level of uncertainty in association with risk factors importance. Sometimes the expert cannot say a definite value as the importance ratio of two risk factors. It may happen because one of the factors maybe a new discovered one in a specific disease and the experts have not enough information about it and its relationship with other factors yet, so they cannot determine the exact ratio in this conditions. Moreover sometimes making decision about these importance ratios depends on a specific statistical data of patients from a specific geographic area in a specific time period. In these cases the problem should be represented by fuzzy approaches. Fuzzy methods deal effectively with these types of issues. Here a fuzzy TOPSIS and a fuzzy GRA method are used to determine the final risk ranking of diabetes complications. The first pair-wise comparison matrix is filled by triangular fuzzy numbers which are determined based on the relative importance between factors taken from related websites and expert's opinion.

A new application of MCDM approaches is considered in this paper for the first time. The introduced algorithms are hybrid fuzzy Multi-Criteria decision making approaches including Fuzzy TOPSIS and fuzzy GRA combinations with AHP used to decide about the relative importance of specific disease complications due to its risk factors.

As previously mentioned fuzzy MCDM approaches are needed to decide the risk rating of diabetes complications. Here the risk factors of diabetes disease are defined as criterions and the associated complications as alternatives. The hierarchical structure of problem is shown in Fig 1.

According to Fig 1, 8 criterions are considered in this paper including high cholesterol, high blood pressure, obesity, physical inactivity, smoking, family history, age and gender. These criterions are defined as $\mathrm{C}_{1}$ to $\mathrm{C}_{8}$ and 5 alternatives including neuropathy, retinopathy, cardiovascular diseases, kidney diseases and foot ulcer and amputation are defined as $A_{1}$ to $A_{5}$ in further sections.

Fuzzy TOPSIS is the first method as an effective way to determine exactly the ranking of alternatives [11]. It takes weight vector of criterions and a comparison matrix between alternatives based on criterions called decision matrix, as input values and produces an importance ranking vector of complications as output. The process is programmed step by step by $\mathrm{R}$ programming language. The problem is that here the first weight vector of criterions is not specified so another Fuzzy MADM approach that is not based on weight vector is needed. AHP is a method which is not based on weight vector of criterions and takes the first pair-wise comparison matrix between criterions as input and produces the weight vector of criterions [11].

In AHP method the pair-wise comparison matrix is a matrix of triangular fuzzy numbers, because as mentioned before, information about pair-wise comparison of criterions or risk factors is available in linguistic terms and should be altered to numeric values by fuzzy methods. So firstly a Fuzzy AHP method is implemented on primary pair-wise comparison matrix of criterions and after obtaining the weight vector of criterions, this output is used by TOPSIS as one of its inputs. The next fuzzy MCDM method included in this paper is fuzzy GRA. Here for the first time, the application of fuzzy GRA in determining the importance degree of complications of a specific disease is implemented by R-programming and the results are described. Like TOPSIS method, a fuzzy AHP method is needed to determine the first weight vector of criterions as one of GRA inputs. 


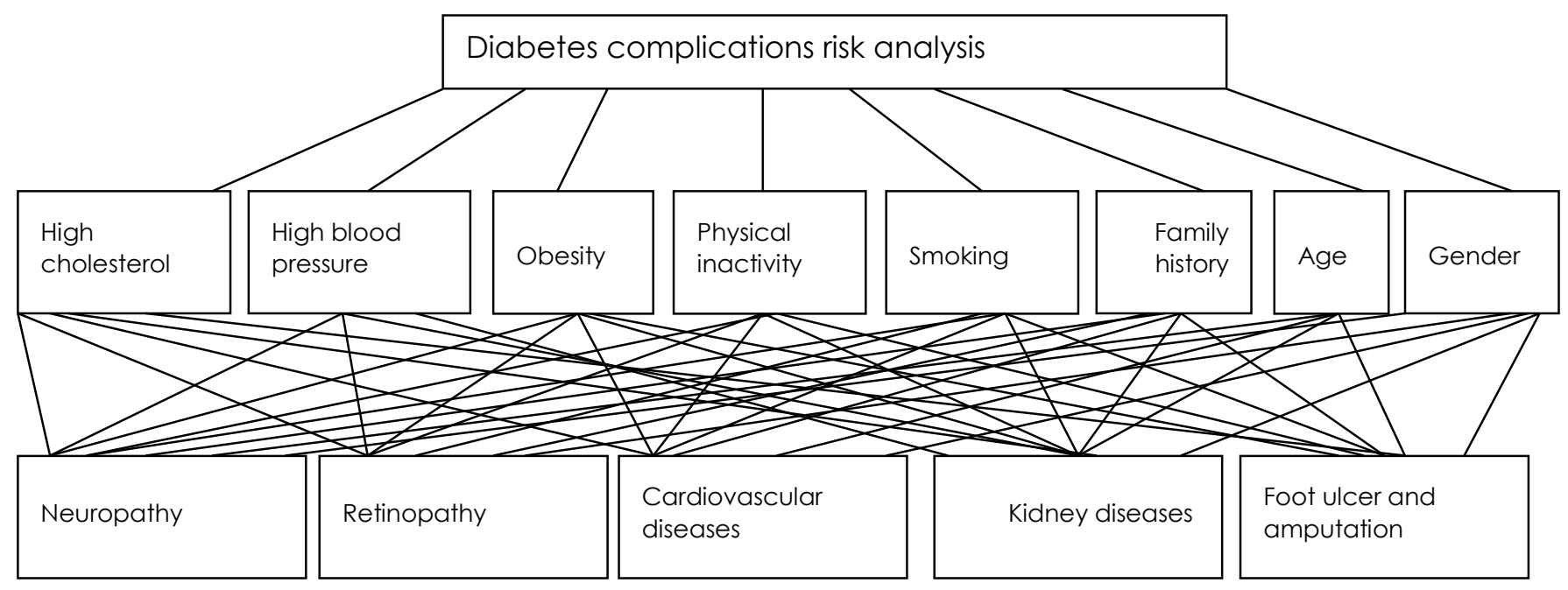

Fig 1: Hierarchical structure of diabetes complications risk analysis problem

\section{MATERIAL AND METHODS}

The problem of diabetes complications risk analysis is represented as a decision making problem in this research and hybrid fuzzy MCDM methods are used to decide the final risk ranking of diabetes complications. As it is shown in Fig 1, diabetes risk factors including high cholesterol, high blood pressure, obesity, physical inactivity, smoking, family history, age and gender, are considered as criterions in this definition and diabetes related complications including neuropathy, retinopathy, cardiovascular diseases, kidney diseases and foot ulcer and amputation, are alternatives.

By this new definition for this kind of problem, MCDM methods can be effectively utilized to solve the problem.

Hybrid fuzzy TOPSIS method

Among MCDM methods AHP and TOPSIS are more prevalent [12]. The difference of these two methods is that AHP is independent of criterions weight vector but TOPSIS is a weight based method. In this research both of methods are used because the first weight vector of criterions is not specified so it should be calculated by an AHP method and then be used as an input value by a TOPSIS method.

AHP needs a pair-wise comparison between criterions; the values of this matrix cannot be specified with high certainty, because as the problem is related to diseases area, there is some level of uncertainty in comparison between criterions and alternatives. Sometimes in comparison between two risk factors of a disease, there may be disagreements between experts or a new risk factor for a specific disease may be discovered and the experts cannot specify an exact value of importance for these risk factors among others. In such conditions fuzzy approaches are effective tools to deal properly with these uncertainties. Here linguistic terms are turned into triangular fuzzy numbers which are easy to be used and represented in mathematical operations.

Values of this matrix are taken from five-point Likert type scale of importance between two elements [11], and are shown in Table 1. In the first phase of the Hybrid fuzzy TOPSIS algorithm, a fuzzy AHP method is implemented on a pair-wise comparison matrix, which is specified by experts and is taken from many related articles and websites [i.e, 7]. In the first step of AHP the values of this matrix are specified as triangular fuzzy numbers. All subsequent calculations are based on fuzzy operations (2).
Table 1: Five-point intensity scale for pair wise comparison linguistic terms and related fuzzy numbers

\begin{tabular}{|l|l|}
\hline The importance degree & Fuzzy number \\
\hline Equally important & $(1,1,1)$ \\
\hline Important & $(2,3,4)$ \\
\hline More important & $(4,5,6)$ \\
\hline Strongly more important & $(6,7,8)$ \\
\hline Absolutely more important & $(8,9,10)$ \\
\hline
\end{tabular}

A triangular fuzzy number is defined by a triple $\left(a_{1}, a_{2}, a_{3}\right)$. The membership function is defined as follows: [13]

$\mu_{\tilde{a}}(x)=\left\{\begin{array}{l}\left(x-a_{1}\right) /\left(a_{2}-a_{1}\right) \text { if } a_{1} \leq x \leq a_{2} \\ \left(a_{3}-x\right) /\left(a_{3}-a_{2}\right) \text { if } a_{2} \leq x \leq a_{3} \\ 0, \text { otherwise. }\end{array}\right.$

Let $\tilde{a}=\left(a_{1}, a_{2}, a_{3}\right)$ and $\tilde{b}=\left(b_{1}, b_{2}, b_{3}\right)$ be two triangular fuzzy numbers, where $a_{1} \leq a_{2} \leq a_{3}$ and $b_{1} \leq b_{2} \leq b_{3}$ the basic

Operations of triangular fuzzy numbers are defined as follows: [16]

(1)Addition

$\tilde{a} \oplus \tilde{b}=\left(a_{1}, a_{2}, a_{3}\right) \oplus\left(b_{1}, b_{2}, b_{3}\right)=\left(a_{1}+b_{1}, a_{2}+b_{2}, a_{3}+b_{3}\right)$

(2) Multiplication:

$\tilde{a} \otimes \tilde{b}=\left(a_{1}, a_{2}, a_{3}\right) \otimes\left(b_{1}, b_{2}, b_{3}\right)=\left(a_{1} \times b_{1}, a_{2} \times b_{2}, a_{3} \times b_{3}\right)_{(3)}$

(3) Inverse

$\frac{1}{\tilde{a}}=\frac{1}{\left(a_{1}, a_{2}, a_{3}\right)}=\left(\frac{1}{a_{3}}, \frac{1}{a_{2}}, \frac{1}{a_{1}}\right)$

(4) Division

$\tilde{a} / \tilde{b}=\left(a_{1}, a_{2}, a_{3}\right) \otimes \frac{1}{\left(b_{1}, b_{2}, b_{3}\right)}=\left(a_{1} / b_{3}, a_{2} / b_{2}, a_{3} / b_{1}\right)$

The pair-wise comparison matrix is shown in Table 2 .

The first weight vector of criterions should be obtained from Table 1. In the next step, the geometric mean of each row is calculated according to (2) and the result is shown in (9).

After a normalization on the results shown in (9) according to (3) the weight vector of criterions is gotten (Table 3 ).

$$
\begin{aligned}
& g_{i}=\sqrt[n]{\operatorname{prod}\left(x_{j}\right)} i=1,2,3 \ldots, m j=1,2,3 \ldots, n \\
& w_{\text {norm }}=\frac{w}{\sum_{i=1}^{n} w_{i}} \text { where } n \text { is the number of criterias }
\end{aligned}
$$


Table 2: Pair-wise comparison matrix between criterions

\begin{tabular}{|l|r|r|r|r|r|r|r|r|}
\hline & C1 & C2 & C3 & C4 & C5 & C6 & C7 & C8 \\
\hline C1 & $(1,1,1)$ & $\left(\frac{1}{3}, \frac{1}{2}, 1\right)$ & $\left(\frac{1}{4}, \frac{1}{3}, \frac{1}{2}\right)$ & $(1,2,3)$ & $(2,3,4)$ & $(4,5,6)$ & $(2,3,4)$ & $(6,7,8)$ \\
\hline C2 & $(1,2,3)$ & $(1,1,1)$ & $\left(\frac{1}{3}, \frac{1}{2}, 1\right)$ & $(2,3,4)$ & $(4,5,6)$ & $(6,7,8)$ & $(4,5,6)$ & $(6,7,8)$ \\
\hline C3 & $(2,3,4)$ & $(1,2,3)$ & $(1,1,1)$ & $(4,5,6)$ & $(6,7,8)$ & $(8,9,10)$ & $(6,7,8)$ & $(8,9,10$ \\
\hline C4 & $\left(\frac{1}{3}, \frac{1}{2}, 1\right)$ & $\left(\frac{1}{4}, \frac{1}{3}, \frac{1}{2}\right)$ & $\left(\frac{1}{6}, \frac{1}{5}, \frac{1}{4}\right)$ & $(1,1,1)$ & $(2,3,4)$ & $(4,5,6)$ & $(2,3,4)$ & $(6,7,8)$ \\
\hline C5 & $\left(\frac{1}{4}, \frac{1}{3}, \frac{1}{2}\right)$ & $\left(\frac{1}{6}, \frac{1}{5}, \frac{1}{4}\right)$ & $\left(\frac{1}{8}, \frac{1}{7}, \frac{1}{6}\right)$ & $\left(\frac{1}{4}, \frac{1}{3}, \frac{1}{2}\right)$ & $(1,1,1)$ & $(2,3,4)$ & $(1,2,3)$ & $(4,5,6)$ \\
\hline C6 & $\left(\frac{1}{6}, \frac{1}{5}, \frac{1}{4}\right)$ & $\left(\frac{1}{8}, \frac{1}{7}, \frac{1}{6}\right)$ & $\left(\frac{1}{10}, \frac{1}{9}, \frac{1}{8}\right)$ & $\left(\frac{1}{6}, \frac{1}{5}, \frac{1}{4}\right)$ & $\left(\frac{1}{4}, \frac{1}{3}, \frac{1}{2}\right)$ & $(1,1,1)$ & $\left(\frac{1}{3}, \frac{1}{2}, 1\right)$ & $(2,3,4)$ \\
\hline C7 & $\left(\frac{1}{4}, \frac{1}{3}, \frac{1}{2}\right)$ & $\left(\frac{1}{6}, \frac{1}{5}, \frac{1}{4}\right)$ & $\left(\frac{1}{8}, \frac{1}{7}, \frac{1}{6}\right)$ & $\left(\frac{1}{4}, \frac{1}{3}, \frac{1}{2}\right)$ & $\left(\frac{1}{3}, \frac{1}{2}, 1\right)$ & $(1,2,3)$ & $(1,1,1)$ & $(2,3,4)$ \\
\hline C8 & $\left(\frac{1}{8}, \frac{1}{7}, \frac{1}{6}\right)$ & $\left(\frac{1}{8}, \frac{1}{7}, \frac{1}{6}\right)$ & $\left(\frac{1}{10}, \frac{1}{9}, \frac{1}{8}\right)$ & $\left(\frac{1}{8}, \frac{1}{7}, \frac{1}{6}\right)$ & $\left(\frac{1}{6}, \frac{1}{5}, \frac{1}{4}\right)$ & $\left(\frac{1}{4}, \frac{1}{3}, \frac{1}{2}\right)$ & $\left(\frac{1}{4}, \frac{1}{3}, \frac{1}{2}\right)$ & $(1,1,1)$ \\
\hline
\end{tabular}

Table 3: Normalized weight vector of criterions

\begin{tabular}{|l|l|}
\hline Criteria & Weight \\
\hline High cholesterol & $(0.083,0.146,0.256)$ \\
\hline High blood pressure & $(0.142,0.237,0.395)$ \\
\hline Obesity & $(0.220,0.353,0.543)$ \\
\hline Physical inactivity & $(0.066,0.109,0.188)$ \\
\hline Smoking & $(0.036,0.060,0.102)$ \\
\hline Family history & $(0.0187,0.029,0.050)$ \\
\hline Age & $(0.026,0.045,0.082)$ \\
\hline Gender & $(0.012,0.018,0.028)$ \\
\hline
\end{tabular}

$g_{1}=\sqrt[8]{\left((1,1,1) \times\left(\frac{1}{3}, \frac{1}{2}, 1\right) \times\left(\frac{1}{4}, \frac{1}{3}, \frac{1}{2}\right) \times(1,2,3) \times(2,3,4) \times(4,5,6) \times(2,3,4) \times(6,7,8)\right)}$

$=\sqrt[8]{(7.992,104.895,1152)}=(1.29,1.79,2.41)$

$g_{2}=\sqrt[8]{(1,2,3) \times(1,1,1) \times\left(\frac{1}{3}, \frac{1}{2}, 1\right) \times(2,3,4) \times(4,5,6) \times(6,7,8) \times(4,5,6) \times(6,7,8)}$

$=\sqrt[8]{(383.616,3675,27648)}=(2.20,2.90,3.71)$

$g_{3}=\sqrt[8]{(2,3,4) \times(1,2,3) \times(1,1,1) \times(4,5,6) \times(6,7,8) \times(8,9,10) \times(6,7,8) \times(8,9,10)}$

$=\sqrt[8]{(0.0104,0.0945,0.75)}=(0.56,0.74,0.96)$

$g_{6}=\sqrt[8]{\left(\frac{1}{6}, \frac{1}{5}, \frac{1}{4}\right) \times\left(\frac{1}{8}, \frac{1}{7}, \frac{1}{6}\right) \times\left(\frac{1}{10}, \frac{1}{9}, \frac{1}{8}\right) \times\left(\frac{1}{6}, \frac{1}{5}, \frac{1}{4}\right) \times\left(\frac{1}{4}, \frac{1}{3}, \frac{1}{2}\right) \times(1,1,1) \times\left(\frac{1}{3}, \frac{1}{2}, 1\right) \times(2,3,4)}$

$=\sqrt[8]{(1.32,10.49,96)}=(1.03,1.34,1.77)$

$g_{5}=\sqrt[8]{\left(\frac{1}{4}, \frac{1}{3}, \frac{1}{2}\right) \times\left(\frac{1}{6}, \frac{1}{5}, \frac{1}{4}\right) \times\left(\frac{1}{8}, \frac{1}{7}, \frac{1}{6}\right) \times\left(\frac{1}{4}, \frac{1}{3}, \frac{1}{2}\right) \times(1,1,1) \times(2,3,4) \times(1,2,3) \times(4,5,6)}$

$=\sqrt[8]{(0.00005,0.00031,0.0026)}=(0.29,0.36,0.47)$ $g_{7}=\sqrt[8]{\left(\frac{1}{4}, \frac{1}{3}, \frac{1}{2}\right) \times\left(\frac{1}{6}, \frac{1}{5}, \frac{1}{4}\right) \times\left(\frac{1}{8}, \frac{1}{7}, \frac{1}{6}\right) \times\left(\frac{1}{4}, \frac{1}{3}, \frac{1}{2}\right) \times\left(\frac{1}{3}, \frac{1}{2}, \frac{1}{1}\right) \times(1,2,3) \times(1,1,1) \times(2,3,4)}$

$=\sqrt[8]{(0.00086,0.0094,0.1249)}=(0.41,0.55,0.77)$

$g_{8}=\sqrt[8]{\left(\frac{1}{8}, \frac{1}{7}, \frac{1}{6}\right) \times\left(\frac{1}{8}, \frac{1}{7}, \frac{1}{6}\right) \times\left(\frac{1}{10}, \frac{1}{9}, \frac{1}{8}\right) \times\left(\frac{1}{8}, \frac{1}{7}, \frac{1}{6}\right) \times\left(\frac{1}{6}, \frac{1}{5}, \frac{1}{4}\right) \times\left(\frac{1}{4}, \frac{1}{3}, \frac{1}{2}\right) \times\left(\frac{1}{4}, \frac{1}{3}, \frac{1}{2}\right) \times(1,1,1)}$

$=\sqrt[8]{(0.0000020,0.0000070,0.000036})=(0.194,0.22,0.27)$

$g_{4}=\sqrt[8]{\left(\frac{1}{3}, \frac{1}{2}, 1\right) \times\left(\frac{1}{4}, \frac{1}{3}, \frac{1}{2}\right) \times\left(\frac{1}{6}, \frac{1}{5}, \frac{1}{4}\right) \times(1,1,1) \times(2,3,4) \times(4,5,6) \times(2,3,4) \times(6,7,8)}$

$=\sqrt[8]{(18432,119070,460800)}=(3.41,4.31,5.10)$

$\sum_{i=1}^{8} g_{i}=(9.384,12.21,15.46) \quad w_{i}=\frac{g_{i}}{\sum g_{i}}$

Table 3 is the first input in the next phase of hybrid TOPSIS algorithm. Another pair-wise comparison matrix between criterions and alternatives is also needed as the second input in TOPSIS method, which is shown in Table 5, values of this table are also triangular fuzzy numbers which are taken from Linguistic terms and related triangle fuzzy numbers for scoring Table 4.

Table 4: Linguistic terms and related triangle fuzzy numbers for

\begin{tabular}{|l|l|}
\hline The scores & Fuzzy number \\
\hline Lowest & $\left(0,0, \frac{1}{6}\right)$ \\
\hline Very low & $\left(0, \frac{1}{6}, \frac{1}{3}\right)$ \\
\hline Low & $\left(\frac{1}{6}, \frac{1}{3}, \frac{1}{2}\right)$ \\
\hline Medium & $\left(\frac{1}{3}, \frac{1}{2}, \frac{2}{3}\right)$ \\
\hline High & $\left(\frac{1}{2}, \frac{2}{3}, \frac{5}{6}\right)$ \\
\hline
\end{tabular}




\begin{tabular}{|l|l|}
\hline Very high & $\left(\frac{2}{3}, \frac{5}{6}, 1\right)$ \\
\hline Highest & $\left(\frac{5}{6}, 1,1\right)$ \\
\hline
\end{tabular}

Hybrid Fuzzy GRA method

Grey Relational Analysis (GRA) [14, 15], is a helpful technique in MCDM problems .It has been successfully applied in solving a variety of MCDM problems. In this paper, for the first time, an extended fuzzy GRA method is proposed to determine about the importance degree of diabetes complications, in which the criterion values are in the form of linguistic variables expressed in interval-valued triangular fuzzy numbers.

In this approach, like the previous one, the first weight vector of criterions should be taken from AHP.

The first pair-wise comparison matrix is changed based on interval-valued fuzzy numbers before being used as input matrix by fuzzy GRA algorithm.

Table 3 is the first input in the fuzzy GRA algorithm which is previously calculated by fuzzy AHP algorithm. Another pairwise comparison matrix between criterions and alternatives is also needed as the second input, like fuzzy TOPSIS algorithm, this table is a matrix with triangular fuzzy numbers but there is a difference here, in fuzzy GRA algorithm interval-valued fuzzy numbers which is illustrated in Fig 2 are used instead of simple triangular fuzzy numbers [16]. For each triangular fuzzy number like $(\mathrm{a}, \mathrm{b}, \mathrm{c})$ a decimal constant is added to upper and lower bounds. This addition makes the bounds wider and as a result, the decision is more accurate and the Uncertainty in the context of the problem could be dealt more effectively. So firstly the fuzzy numbers of Table 4 should be altered into intervalvalued fuzzy numbers which is shown in Table 6 , and then this matrix and weight vector of criterions (Table 3 ) are used as input matrices by GRA algorithm.

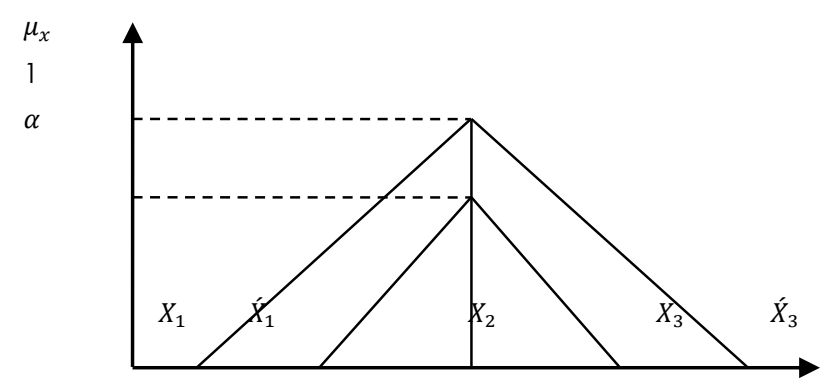

Fig 2: Interval-valued triangular fuzzy number definition

\section{RESULTS}

\section{Hybrid Fuzzy TOPSIS algorithm}

Table 3 and Table 5 are inputs of a program written by Rprogramming to obtain the final risk ranking of diabetes complications or alternatives. The result of algorithm implemented by R-programming is described with details: Step1. TOPSIS input matrices (Table 4 and Table 5) should be prepared and saved according to following instructions:

A. Insert the weight vector into excel and save this document as text (tab delimited format)

B. Insert the pairwise comparison matrix between criterias and alternatives and save it as text (tab delimited format)

These excel inputs are then imported in Rgui which is asked by name from the user in windows shown in Fig 3.

As a result the inputs are shown in editable tables in which the user can add or remove fields and records or change the contents (Fig 3).

Table 5: Decision matrix between alternatives based on criterions in TOPSIS algorithm

\begin{tabular}{|r|r|r|r|r|r|r|r|r|}
\hline & C1 & C2 & C3 & C4 & C5 & C6 & C7 & C8 \\
\hline A1 & $\left(0, \frac{1}{6}, \frac{1}{3}\right)$ & $\left(\frac{1}{6}, \frac{1}{3}, \frac{1}{2}\right)$ & $\left(\frac{1}{2}, \frac{2}{3}, \frac{5}{6}\right)$ & $\left(\frac{1}{2}, \frac{2}{3}, \frac{5}{6}\right)$ & $\left(\frac{1}{3}, \frac{1}{2}, \frac{2}{3}\right)$ & $\left(\frac{1}{6}, \frac{1}{3}, \frac{1}{2}\right)$ & $\left(\frac{1}{3}, \frac{1}{2}, \frac{2}{3}\right)$ & $\left(0, \frac{1}{6}, \frac{1}{3}\right)$ \\
\hline A2 & $\left(\frac{1}{6}, \frac{1}{3}, \frac{1}{2}\right)$ & $\left(\frac{1}{3}, \frac{1}{2}, \frac{2}{3}\right)$ & $\left(\frac{1}{3}, \frac{1}{2}, \frac{2}{3}\right)$ & $\left(0, \frac{1}{6}, \frac{1}{3}\right)$ & $\left(\frac{1}{2}, \frac{2}{3}, \frac{5}{6}\right)$ & $\left(\frac{1}{3}, \frac{1}{2}, \frac{2}{3}\right)$ & $\left(\frac{1}{3}, \frac{1}{2}, \frac{2}{3}\right)$ & $\left(\frac{1}{6}, \frac{1}{3}, \frac{1}{2}\right)$ \\
\hline A3 & $\left(\frac{5}{6}, 1,1\right)$ & $\left(\frac{2}{3}, \frac{5}{6}, 1\right)$ & $\left(\frac{5}{6}, 1,1\right)$ & $\left(\frac{2}{3}, \frac{5}{6}, 1\right)$ & $\left(\frac{2}{3}, \frac{5}{6}, 1\right)$ & $\left(\frac{1}{2}, \frac{2}{3}, \frac{5}{6}\right)$ & $\left(\frac{2}{3}, \frac{5}{6}, 1\right)$ & $\left(\frac{1}{6}, \frac{1}{3}, \frac{1}{2}\right)$ \\
\hline A4 & $\left(\frac{2}{3}, \frac{5}{6}, 1\right)$ & $\left(\frac{1}{2}, \frac{2}{3}, \frac{5}{6}\right)$ & $\left(\frac{1}{6}, \frac{1}{3}, \frac{1}{2}\right)$ & $\left(\frac{1}{6}, \frac{1}{3}, \frac{1}{2}\right)$ & $\left(\frac{1}{2}, \frac{2}{3}, \frac{5}{6}\right)$ & $\left(\frac{1}{3}, \frac{1}{2}, \frac{2}{3}\right)$ & $\left(\frac{1}{3}, \frac{1}{2}, \frac{2}{3}\right)$ & $\left(\frac{1}{6}, \frac{1}{3}, \frac{1}{2}\right)$ \\
\hline A5 & $\left(0, \frac{1}{6}, \frac{1}{3}\right)$ & $\left(\frac{1}{6}, \frac{1}{3}, \frac{1}{2}\right)$ & $\left(\frac{1}{6}, \frac{1}{3}, \frac{1}{2}\right)$ & $\left(\frac{1}{3}, \frac{1}{2}, \frac{2}{3}\right)$ & $\left(\frac{1}{3}, \frac{1}{2}, \frac{2}{3}\right)$ & $\left(\frac{1}{6}, \frac{1}{3}, \frac{1}{2}\right)$ & $\left(\frac{1}{6}, \frac{1}{3}, \frac{1}{2}\right)$ & $\left(0, \frac{1}{6}, \frac{1}{3}\right)$ \\
\hline
\end{tabular}

Step2. Normalized fuzzy decision matrix calculation [9]: In this step the values of decision matrix (Table 4) should be normalized based on fuzzy arithmetic.

The normalization operation is as follows:

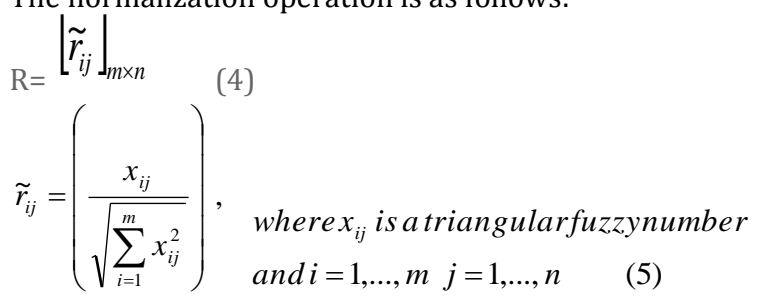

The result normalized matrix is shown in Table 5.
Each triangular fuzzy number in Table 5 is denoted as $(a, b, c)$ in this operation and " $\mathrm{i}$ " index is changing from 1 to $\mathrm{m}(\mathrm{m}$ is the number of alternatives) and $\mathrm{j}$ is changing from 1 to $\mathrm{n}$ ( $\mathrm{n}$ is the number of criterions). The result matrix is shown in Table 6 .

Step3. Weighted normalized fuzzy decision matrix calculation [11]: This matrix is calculated as follows:

$$
\tilde{V}=\left[\tilde{v}_{i j}\right]_{m \times n} \quad \text { (7) } \quad \tilde{v}_{i j}=\tilde{r}_{i j} \times \tilde{w}_{j}
$$

$\mathrm{W}$ is the weight vector of criterions (Table 3 ) and each column in Table 6 is multiplied by its related weight value. The result matrix is shown in Table 7 . 
Table 6: Normalized decision matrix in TOPSIS algorithm

\begin{tabular}{|c|c|c|c|c|c|c|c|c|}
\hline & $\mathrm{C}_{1}$ & $\mathbf{C}_{2}$ & $\mathrm{C}_{3}$ & $\mathrm{C}_{4}$ & $\mathrm{C}_{5}$ & $\mathrm{C}_{6}$ & $\mathrm{C}_{7}$ & $\mathrm{C}_{8}$ \\
\hline $\mathrm{A}_{1}$ & $(0,0.12,0.31)$ & $(0.10,0.26,0.54)$ & $(0.30,0.48,0.79)$ & $(0.31,0.54,0.91)$ & $(0.18,0.34,0.61)$ & $(0.11,0.31,0.69)$ & $(0.20,0.40,0.74)$ & $(0,0.26,1.15)$ \\
\hline $\mathrm{A}_{2}$ & $(0.10,0.24,0.46)$ & $(0.20,0.39,0.72)$ & $(0.20,0.36,0.63)$ & $(0,0.13,0.36)$ & $(0.27,0.46,0.77)$ & $(0.23,0.46,0.91)$ & $(0.20,0.40,0.74)$ & $(0.17,0.53,1.73)$ \\
\hline $\mathrm{A}_{3}$ & $(0.53,0.73,0.93)$ & $(0.41,0.65,1.08)$ & $(0.51,0.72,0.95)$ & $(0.42,0.67,1.09)$ & $(0.37,0.57,0.92)$ & $(0.34,0.61,1.14)$ & $(0.41,0.67,1.11)$ & $(0.17,0.53,1.73)$ \\
\hline $\mathrm{A}_{4}$ & $(0.42,0.61,0.93)$ & $(0.30,0.52,0.9)$ & $(0.10,0.24,0.47)$ & $(0.10,0.27,0.54)$ & $(0.27,0.46,0.77)$ & $(0.23,0.46,0.91)$ & $(0.20,0.40,0.74$ & $(0.17,0.53,1.73)$ \\
\hline $\mathrm{A}_{5}$ & $(0,0.12,0.31)$ & $(0.10,0.26,0.54)$ & $(0.10,0.24,0.47)$ & $(0.21,0.40,0.73)$ & $(0.18,0.34,0.61)$ & $(0.11,0.31,0.69)$ & $(0.10,0.26,0.55)$ & $(0,0.26,1.15)$ \\
\hline
\end{tabular}

Table 7: Weighted normalized decision matrix in TOPSIS algorithm

\begin{tabular}{|c|c|c|c|c|c|c|c|c|}
\hline & $\mathrm{C}_{1}$ & $\mathrm{C}_{2}$ & $\mathrm{C}_{3}$ & $\mathrm{C}_{4}$ & $\mathrm{C}_{5}$ & $\mathrm{C}_{6}$ & $\mathbf{C}_{7}$ & $\mathrm{C}_{8}$ \\
\hline $\mathrm{A}_{1}$ & $(0,0.005,0.02)$ & $(0.004,0.01,0.06)$ & $(0.02,0.05,0.13)$ & $(0.006,0.01,0.05)$ & $(0.002,0.006,0.01)$ & $0.0006,0.002,0.01)$ & $(0.001,0.005,0.01)$ & $(0,0.001,0.009)$ \\
\hline $\mathrm{A}_{2}$ & $(0.002,0.01,0.03)$ & $(0.009,0.28,0.87)$ & $(0.01,0.03,0.10)$ & $(0,0.004,0.02)$ & $(0.003,0.008,0.02)$ & $(0.001,0.004,0.01)$ & $(0.001,0.005,0.01)$ & $(0.0006,0.002,0.01)$ \\
\hline $\mathrm{A}_{3}$ & $(0.01,0.03,0.07)$ & $(0.01,0.04,0.01)$ & $(0.03,0.07,0.16)$ & $(0.008,0.02,0.06)$ & $(0.004,0.01,0.02)$ & $(0.002,0.005,0.01)$ & $(0.003,0.009,0.02)$ & $(0.0006,0.002,0.01)$ \\
\hline $\mathrm{A}_{4}$ & $(0.01,0.02,0.07)$ & $(0.01,0.03,0.11)$ & $(0.007,0.02,0.07)$ & $0.002,0.009,0.03)$ & $(0.003,0.008,0.02)$ & $(0.001,0.004,0.01)$ & $(0.001,0.005,0.01)$ & $(0.0006,0.002,0.01)$ \\
\hline $\mathrm{A}_{5}$ & $(0,0.005,0.02)$ & $(0.004,0.01,0.06)$ & $(0.007,0.02,0.07)$ & $(0.004,0.01,0.04)$ & $(0.002,0.006,0.01)$ & $(0.0006,0.002,0.01)$ & $0.0008,0.003,0.01)$ & $(0,0.001,0.009)$ \\
\hline
\end{tabular}

Step4. Fuzzy positive and negative ideal solutions [11]:

The positive and negative ideal solutions are calculated as follows:

$A^{*}=\left\{v_{1}^{*}, v_{2}^{*}, \ldots, v_{n}^{*}\right\}$

$=\left\{\left(\max v_{i j} \mid j=1, \ldots, n\right) \mid i=1, \ldots, m\right\}$

$A^{-}=\left\{v_{1}^{-}, v_{2}^{-}, \ldots, v_{n}^{-}\right\}$

$=\left\{\left(\min v_{i j} \mid j=1, \ldots, n\right) \mid i=1, \ldots, m\right\}$

For each column the maximum fuzzy number is selected as the fuzzy positive ideal solution and the minimum one is selected as the fuzzy negative ideal solution.

To find the maximum fuzzy number between many triangular fuzzy numbers, firstly the decision is based on right side of fuzzy number, then on middle side and at last the left side and the reverse operation is happened for minimum fuzzy number. Positive and negative ideal solutions are shown in Table 8 and Table 9 respectively.

Table 8: Positive Ideal Solution for criterions (PIS) in TOPSIS

\begin{tabular}{|c|c|c|c|c|c|c|c|c|}
\hline & $\mathbf{C}_{1}$ & $\mathbf{C}_{2}$ & $\mathrm{C}_{3}$ & $\mathrm{C}_{4}$ & $\mathrm{C}_{5}$ & $\mathrm{C}_{6}$ & $\mathrm{C}_{7}$ & $\mathrm{C}_{8}$ \\
\hline PIS & 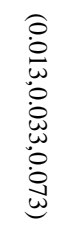 & $\begin{array}{l}\hat{O} \\
\dot{0} \\
\infty \\
0 \\
0 \\
0 \\
\infty \\
0 \\
\dot{0} \\
.0\end{array}$ & 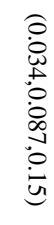 & 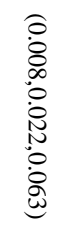 & $\begin{array}{l}0 \\
0 \\
0 \\
0 \\
0 \\
0 \\
0 \\
0 \\
0 \\
0 \\
0\end{array}$ & $\begin{array}{l}0 \\
0 \\
0 \\
0 \\
0 \\
0 \\
0 \\
0.0 \\
0 \\
0 \\
0 \\
0\end{array}$ & $\begin{array}{l}\text { oे } \\
\dot{0} \\
0 \\
0 \\
0 \\
0 \\
0 \\
0 \\
0 \\
0 \\
0\end{array}$ & $\begin{array}{l}0 \\
0 \\
0 \\
0 \\
0 \\
0 \\
0 \\
0\end{array}$ \\
\hline
\end{tabular}

Table 9: Negative Ideal Solution for criterions (NIS) in

\begin{tabular}{|c|c|c|c|c|c|c|c|c|}
\hline \multicolumn{9}{|c|}{ TOPSIS algorithm } \\
\hline & $\mathbf{C}_{1}$ & $\mathrm{C}_{2}$ & $\mathrm{C}_{3}$ & $\mathrm{C}_{4}$ & $\mathrm{C}_{5}$ & $\mathrm{C}_{6}$ & $\mathrm{C}_{7}$ & $\mathrm{C}_{8}$ \\
\hline NIS & $\begin{array}{l}\hat{O} \\
0 \\
0 \\
0 \\
0 \\
0 \\
0 \\
0 \\
0 \\
\end{array}$ & $\begin{array}{l}0 \\
0 \\
0 \\
0 \\
0 \\
0 \\
0 \\
0 \\
0 \\
0 \\
0 \\
0 \\
0\end{array}$ & $\begin{array}{l}0 \\
0 \\
0 \\
0 \\
0 \\
0 \\
0 \\
0 \\
0 \\
0 \\
0 \\
0 \\
0 \\
0\end{array}$ & 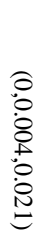 & $\begin{array}{l}0 \\
0 \\
0 \\
0 \\
0 \\
0 \\
0 \\
0 \\
0 \\
0 \\
0 \\
0 \\
0\end{array}$ & $\begin{array}{l}0 \\
\dot{8} \\
0 \\
0 \\
0 \\
0 \\
0 \\
0 \\
0 \\
0 \\
0 \\
0 \\
0\end{array}$ & $\begin{array}{l}0 \\
\dot{0} \\
8 \\
0 \\
0 \\
0 \\
0 \\
0 \\
0 \\
0 \\
0 \\
0 \\
\end{array}$ & $\begin{array}{l}\hat{O} \\
\dot{0} \\
\dot{0} \\
\stackrel{0}{0} \\
0 \\
0 \\
0\end{array}$ \\
\hline
\end{tabular}

Step 5: distances from positive and negative ideal solutions calculation [11]:

$$
\begin{aligned}
& d_{i}^{*}=\sum_{n}^{j=1} d\left(\tilde{v}_{i j}, \tilde{v}_{j}^{*}\right) \\
& d_{i}^{-}=\sum_{n}^{j=1} d\left(\tilde{v}_{i j}, \tilde{v}_{j}^{-}\right)
\end{aligned}
$$

For each alternative this distance is calculated based on a fuzzy distance measurement. In this research two fuzzy distance measurements are used separately in this step and the results are obtained with both measurements.

The first measurement is arithmetic one in which the distance between two fuzzy numbers is calculated based on fuzzy subtraction. And the second one is integral distance in which the distance is calculated based on (13).

$$
d(\tilde{a}, \tilde{b})=\left(\int_{0}^{1}\left[\left(a_{\lambda}^{L:}-b_{\lambda}^{L}\right)^{2}+\left(a_{\lambda}^{R}-b_{\lambda}^{R}\right)^{2}\right] d_{\lambda}\right)^{\frac{1}{2}}
$$

$d^{*}$ and $d^{-}$for arithmetic and integral distance measurements are shown in Table 10 and Table 11, respectively. 


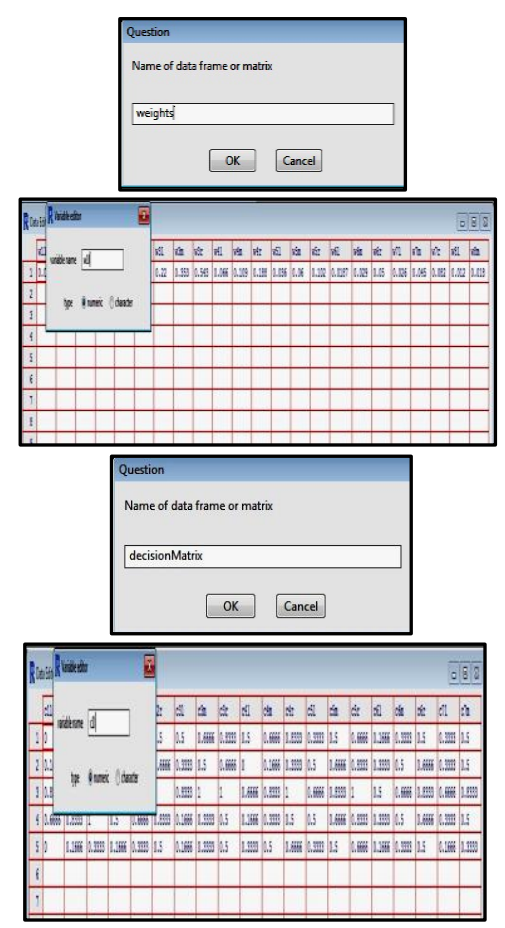

Fig 3: Input windows in Fuzzy TOPSIS and fuzzy GRA methods in Rgui

Table 10: Distances from ideal solutions for alternatives based on arithmetic distance measurement in TOPSIS algorithm

\begin{tabular}{|r|r|r|r|r|r|}
\hline & $\mathbf{A}_{1}$ & $\mathbf{A} 2$ & $\mathbf{A} 3$ & $\mathbf{A}_{4}$ & $\mathbf{A}_{5}$ \\
\hline $\mathbf{d}^{*}$ & 0.249 & 0.246 & 0.269 & 0.254 & 0.245 \\
\hline $\mathbf{d}^{*}$ & 0.182 & 0.170 & 0.245 & 0.183 & 0.150 \\
\hline
\end{tabular}

Table 11: Distances from ideal solutions for alternatives based on integral distance measurement in TOPSIS algorithm

\begin{tabular}{|l|l|l|l|l|l|}
\hline & $\mathbf{A}_{\mathbf{1}}$ & $\mathbf{A}_{\mathbf{2}}$ & $\mathbf{A}_{3}$ & $\mathbf{A} 4$ & $\mathbf{A} 5$ \\
\hline $\mathbf{d}^{*}$ & 0.0435 & 0.0436 & 0.0424 & 0.0437 & 0.0445 \\
\hline $\mathbf{d}^{-}$ & 0.04291 & 0.04259 & 0.04466 & 0.04295 & 0.04247 \\
\hline
\end{tabular}

Step 6: closeness coefficient calculation [11]:

This value is calculated as follows for each alternative:

$c c_{i}=\frac{d_{i}^{-}}{d_{i}^{*}+d_{i}^{-}}, i=1, \ldots, m$

The results for both measurements are shown in Table 12 and Table 13 respectively.

Table 12: Closeness Coefficient for alternatives based on arithmetic distance measurement in TOPSIS algorithm

\begin{tabular}{|l|l|l|l|l|l|}
\hline & $\mathbf{A}_{\mathbf{1}}$ & $\mathbf{A}_{\mathbf{2}}$ & $\mathbf{A}_{\mathbf{3}}$ & $\mathbf{A}_{\mathbf{4}}$ & $\mathbf{A}_{\mathbf{5}}$ \\
\hline $\mathbf{C C}$ & 0.421 & 0.408 & 0.476 & 0.419 & 0.380 \\
\hline
\end{tabular}

Table 13: Closeness Coefficient for alternatives based on integral distance measurement in TOPSIS algorithm

\begin{tabular}{|l|l|l|l|l|l|}
\hline & $\mathbf{A}_{1}$ & $\mathbf{A}_{2}$ & $\mathbf{A}_{3}$ & $\mathbf{A}_{4}$ & $\mathbf{A}_{5}$ \\
\hline $\mathbf{C C}$ & 0.4964 & 0.4939 & 0.5128 & 0.4952 & 0.4882 \\
\hline
\end{tabular}

Step 7: final ranking:

The final ranking of alternatives is calculated according to closeness coefficient values for both measurements (Table 14, Table 15).

Table 14: Normalized Closeness Coefficient and final ranking for alternatives based on arithmetic distance measurement in TOPSIS algorithm

\begin{tabular}{|r|r|r|r|r|r|}
\hline & $\mathbf{A}_{3}$ & $\mathbf{A}_{\mathbf{1}}$ & $\mathbf{A}_{4}$ & $\mathbf{A}_{2}$ & $\mathbf{A}_{5}$ \\
\hline Ranking & 0.226 & 0.200 & 0.199 & 0.193 & 0.180 \\
\hline
\end{tabular}

Table 15: Normalized Closeness Coefficient and final ranking for alternatives based on integral distance measurement in TOPSIS algorithm

\begin{tabular}{|r|r|r|r|r|r|}
\hline & $\mathbf{A 3}$ & $\mathbf{A} 1$ & $\mathbf{A}_{4}$ & $\mathbf{A} 2$ & $\mathbf{A} 5$ \\
\hline Ranking & 0.2062 & 0.19964 & 0.19915 & 0.19863 & 0.19634 \\
\hline
\end{tabular}

\section{Hybrid Fuzzy GRA algorithm}

In this paper another hybrid MCDM approach is implemented on diabetes complications risk analysis, this method is a combination of Fuzzy AHP and Fuzzy GRA methods. Like the previous method, firstly a fuzzy AHP method is used to obtain the first weight vector of criterions (Table 3), which is one of the fuzzy GRA inputs. The next input in this algorithm is the decision matrix between criterions and alternatives which is shown in Table 5. In this algorithm, fuzzy numbers on Table 5 are changed to interval-valued triangular fuzzy numbers for greater accuracy [16]. Here the constant number added to fuzzy numbers bound is 0.1 . So the decision matrix between criterions and alternatives is altered to Table 16 . The result of algorithm implemented by R-programming is described with details:

Step1. Decision matrix normalization [11]:

The normalized performance rating can be calculated as:

$$
\tilde{r}_{i j}=\left(\frac{x_{i j}}{\sqrt{\sum_{i=1}^{m} x_{i j}^{2}}}\right), \quad \begin{aligned}
& \text { wherex }_{i j} \text { is atriangularfuzzynumber } \\
& \text { and } i=1, \ldots, m j=1, \ldots, n
\end{aligned}
$$

where, $\tilde{r}_{i j}$ is denoted as $\left\lfloor\left(g_{i j}, g_{i j}^{\prime}\right), h_{i j},\left(l_{i j}, l_{i j}^{\prime}\right)\right\rfloor$, hence the normalized decision matrix $\widetilde{R}$ can be obtained (Table 17).

Step2. Determining the reference series [16]: The reference series can be defined as: $R_{0}=\left(r_{01}, r_{02}, \ldots, r_{0 n}\right)=([(1,1), 1,(1,1)],[(1,1), 1,(1,1)], \ldots,[(1,1), 1,(1,1)])$ (16)

Step3. Distance from the reference value [16]: 
In this step the distance between reference value and each comparison value is calculated as follows:

$$
\begin{aligned}
\delta_{i j}^{(1)} & =\sqrt{\frac{1}{3}\left[\left(g_{i j}^{\prime}-1\right)^{2}+\left(h_{i j}-1\right)^{2}+\left(l_{i j}^{\prime}-1\right)^{2}\right]} \\
\delta_{i j}^{(2)} & =\sqrt{\frac{1}{3}\left[\left(g_{i j}-1\right)^{2}+\left(h_{i j}-1\right)^{2}+\left(l_{i j}-1\right)^{2}\right]}
\end{aligned}
$$

This distance value is an interval value denoted as $\bar{\delta}_{i j}=\left\lfloor\delta_{i j}^{(1)}, \delta_{i j}^{(2)}\right\rfloor$ than just converting immediately to a crisp value. At the same time their maximum and minimum values could be obtained as follows:

$$
\begin{aligned}
& \delta_{\max }^{(1)}=\max _{i j} \delta_{i j}^{(1)}, \delta_{\max }^{(2)}=\max _{i j} \delta_{i j}^{2} \\
& \delta_{\min }^{(1)}=\min _{i j} \delta_{i j}^{(1)} \\
& \delta_{\min }^{(2)}=\min _{i j} \delta_{i j}^{(2)}, i=1,2, \ldots, m ; j=1,2, \ldots, n
\end{aligned}
$$

\section{(20)}

The distance of each alternative from the reference series is calculated and the result is shown in Table 18.

Step4. Grey relational coefficient calculation [16]: These coefficients are calculated as follows:

$$
\begin{aligned}
& \xi_{i j}^{(1)}=\frac{\delta_{\min }^{(1)}+\zeta \delta_{\max }^{(1)}}{\delta_{i j}^{(1)}+\zeta \delta_{\max }^{(1)}} \\
& \xi_{i j}^{(2)}=\frac{\delta_{\min }^{(2)}+\zeta \delta_{\max }^{(2)}}{\delta_{i j}^{(2)}+\zeta \delta_{\max }^{(2)}}, i=1,2, \ldots, m ; j=1,2, \ldots, n
\end{aligned}
$$

The result is shown in Table 19.

Step5. Grey relational grade estimation [16]:

$$
\begin{aligned}
\gamma_{i}^{(1)} & =\sum_{j=1}^{n} w_{j} \xi_{i j}^{(1)} \\
\gamma_{i}^{(2)} & =\sum_{j=1}^{n} w_{j} \xi_{i j}^{(2)}, i=1,2, \ldots, m
\end{aligned}
$$

By bringing the obtained weights from fuzzy AHP algorithm (Table 3 ) into Eq. $(23,24)$, the grey relational grade is gotten (Table 21 ).

Step 6. Defuzzification operation [17]:

In this step, values of Table 21 which are triangular fuzzy numbers should be changed into crisp numbers because in the next step they are going to be compared and used in calculation of the likelihood of pair wise comparison between alternatives and finally the goal is to gain a ranking between 5 alternatives with deterministic values. Here the most prevalent defuzzification method called Centroid method is utilized. The Centroid of a fuzzy number is calculated as follows:

$\bar{x}_{o}(\tilde{A})=\frac{\int_{a_{1}}^{a_{3}} x \mu_{\tilde{A}}(x) d_{x}}{\int_{a_{1}}^{a_{3}} \mu_{\tilde{A}}(x) d_{x}}$

This value is the integral of membership function of a fuzzy number which is defined in (1).

Each triangular fuzzy number in Table 21 has a membership function and after applying (25) on it, a crisp value is obtained which is the Centroid point of the triangle formed by fuzzy number on the axis.

The result on grey relational grades is as follows:

$$
\gamma_{1}^{(1)}=0.5880, \gamma_{1}^{(2)}=0.7210
$$

$$
\begin{aligned}
& \gamma_{2}^{(1)}=0.5669, \quad \gamma_{2}^{(2)}=0.7083 \\
& \gamma_{3}^{(1)}=0.8101, \quad \gamma_{3}^{(2)}=0.9538 \\
& \gamma_{4}^{(1)}=0.6603, \gamma_{4}^{(2)}=0.7843 \\
& \gamma_{5}^{(1)}=0.5285, \quad \gamma_{5}^{(2)}=0.6507
\end{aligned}
$$

That is, the grey relational grades of the alternatives are interval numbers [12]:

$$
\begin{gathered}
\bar{\gamma}_{1}=[0.5880,0.7210], \bar{\gamma}_{2}=[0.5669,0.7083] \\
\bar{\gamma}_{3}=[0.8101,0.9538], \bar{\gamma}_{4}=[0.6603,0.7843] \\
\bar{\gamma}_{5}=[0.5285,0.6507]
\end{gathered}
$$

Step7. Ranking of alternatives [16]:

Alternative As being not inferior to At is denoted by $A_{s} \geq$ $A_{t}$. The likelihood of $A_{s} \geq A_{t}$ is defined and measured by that of $\bar{\gamma}_{s} \geq \bar{\gamma}_{t}$, where $\bar{\gamma}_{s}$ and $\bar{\gamma}_{t}$ are corresponding grey relational grade interval numbers of alternatives $A_{s}$ and $A_{t}$, respectively. Using the concept of likelihood for interval numbers, the likelihood of $A_{s} \geq A_{t}$, for alternatives $A_{s}$ and $A_{t}$ can be determined as follows:

$$
\begin{gathered}
p\left(A_{s} \geq A_{t}\right)=p\left(\bar{\gamma}_{s} \geq \bar{\gamma}_{t}\right) \\
=\max \left\{1-\max \left\{\frac{\gamma_{t}^{(2)}-\gamma_{s}^{(1)}}{L\left(\bar{\gamma}_{s}\right)+L\left(\bar{\gamma}_{t}\right)}, 0\right\}, 0\right\}
\end{gathered}
$$

Where $\bar{\gamma}_{s}=\left[\gamma_{s}^{(1)}, \gamma_{s}^{(2)}\right], \bar{\gamma}_{t}=\left[\gamma_{t}^{(1)}, \gamma_{t}^{(2)}\right]$,

$L\left(\bar{\gamma}_{s}\right)=\gamma_{s}^{(2)}-\gamma_{s}^{(1)}, L\left(\bar{\gamma}_{t}\right)=\gamma_{t}^{(2)}-\gamma_{t}^{(1)}$.

Thus, the likelihood matrix can be obtained and expressed as follows:

$$
P=\left(p_{s t}\right)_{m \times m}=\left[\begin{array}{cccc}
p_{11} & p_{12} & & p_{1 m} \\
p_{21} & p_{22} & \cdots & p_{2 m} \\
& \vdots & \ddots & \vdots \\
p_{m 1} & p_{m 2} & \cdots & p_{m m}
\end{array}\right]
$$

where $p_{s t}=p\left(A_{s} \geq A_{t}\right)(s, t=1,2, \ldots, m)$ for alternatives $A_{s}$ and $A_{t}$.

The likelihood matrix of 5 alternatives is calculated and the result is as follows:

$$
\left(p_{s t}\right)_{m \times m}=\left[\begin{array}{ccccc}
0.5 & 0.557 & 0 & 0.236 & 0.760 \\
0.442 & 0.5 & 0 & 0.180 & 0.689 \\
1 & 1 & 0.5 & 1 & 1 \\
0.763 & 0.819 & 0 & 0.5 & 1 \\
0.239 & 0.310 & 0 & 0 & 0.5
\end{array}\right]
$$

As the matrix $\mathrm{P}$ is a fuzzy complementary judgment matrix, optimal degrees of membership for alternatives $\operatorname{Ai}(\mathrm{i}=1,2, \ldots, \mathrm{m})$ can be defined as follows $[16]$ :

$$
V_{i}=\frac{1}{m(m-1)}\left(\sum_{r=1}^{m} p_{i r}+\left(\frac{m}{2}-1\right)\right)
$$

Thus a sort vector $V=\left(V_{1}, V_{2}, \ldots V_{m}\right)$ of the alternatives can be obtained:

$$
V=(0.1777,0.1656,0.30,0.2291,0.1274)
$$

Finally, a ranking of alternatives $A_{i}(i=1,2, \ldots, m)$ according to vector $\mathrm{V}$ can be obtained:

$$
\begin{gathered}
A_{3}(0.30) \geq A_{4}(0.229) \geq A_{1}(0.177) \geq A_{2}(0.165) \\
\geq A_{5}(0.127)
\end{gathered}
$$

\section{CONCLUSION}

Multi-criteria decision making methods are effective tools in variable problems especially when many alternatives are available and the best one should be selected based on many related criterions.

But in this paper, for the first time, a new application of MCDM problems is considered. Two prevalent MCDM approaches called TOPSIS and GRA methods were 
implemented on diabetes complications as alternatives based on its risk factors as criterions and the final result is a ranking of complications due to their significance and importance between diabetics.

There is some level of uncertainty in the scope of research, mainly in determining the first pair-wise comparison between risk factors as criterions.

To dealing effectively with uncertainty of the problem, the fuzzy versions of MCDM approaches mentioned above, was utilized here.

Firstly a fuzzy TOPSIS algorithm implemented by Rprogramming was utilized and based on different distance measurements used; two different rankings were obtained for 5 diabetes complications including: neuropathy, retinopathy, cardiovascular diseases, kidney diseases and foot ulcer and amputation. The sort of ranking for two different distance measurements in fuzzy TOPSIS were the same but with a little different in weights or ranking values of alternatives. As it was expected the ranking based on integral distance measurement is more accurate and the values are so closed together.

Another fuzzy MCDM approach called fuzzy GRA method was implemented by R-programming here. This method is a more complicated one compared to fuzzy TOPSIS method. In GRA method values of the first pair-wise comparison between criterions were defined in intervalvalued fuzzy numbers, this puts more accuracy on the problem and the final ranking obtained from this method was a little different in sorting and weights of alternatives compared to fuzzy TOPSIS method.

In both methods the most important complication in the problem was cardiovascular diseases and this fact is reasonable due to the first pair-wise comparison where the most important risk factor was high cholesterol which is a very important risk factor in heart problems.

The next important complication in fuzzy TOPSIS method was neuropathy, which is affected by physical inactivity, obesity and smoking. But in fuzzy GRA method, it was kidney diseases which is affected by high blood pressure and smoking. Generally, the results of GRA method, because of higher levels of accuracy, were more accurate according to the first comparison between risk factors and the first weight vector of criterions obtained from fuzzy AHP method.

\section{ACKNOWLEDGEMENT}

We are particularly grateful for the assistance given by Dr. Lotfollah.Saed, Professor of Endocrinology and Metabolism.
4. Cervoni B. An overview of type 2 diabetes [Internet]. 2010 [updated 2017 Oct 11; cited 2014 May 22]. Available from: http://diabetes.about.com

5. Diabetes and diabetes prevention [Internet]. 2009 [updated 2018 Apr 01; cited 2014 May 25]. Available from: www.health.ny.gov/diseases/conditions/diabetes

6. Centers for Disease Control and Prevention. Diabetes [Internet]. 2008 [updated 2018 Apr 20; cited 2014 May 25]. Available from: http://www.cdc.gov/diabetes

7. American Diabetes Association. Diabetes [Internet]. 2009 [cited 2014 May 11]. Available from: http://www.diabetes.org

8. National diabetes education program [Internet]. 2008 [cited 2014 Agu 11]. Available from: http://ndep.nih.gov/

9. Diabetes research, care and education [Internet]. 2006 [cited 2014 Aug 11]. Available from: http://www.joslin.org/

10. American Heart Association [Internet]. 2000 [cited 2014 Aug 11]. Available from: http://www.heart.org/

11. LU J, Zhang G, Ruan D, Wu F. Multi-objective group decision making: Methods, software and applications with fuzzy set techniques. Imperial College Press, London. 2007.

12. Hwang CL, Yoon K. Multiple attribute decision making: Methods and applications. Springer-Verlag, Berlin. 1981.

13. Nagoor Gani A, Assarudeen SNM. A new operation on triangular fuzzy number for solving fuzzy linear programming problem. Applied Mathematical Sciences. 2012; 6(11): 525-32.

14. Deng JL. Introduction to grey system theory. The Journal of Grey Systems. 1989; 1(1): 1-24.

15. Deng JL. Grey system theory. Huazhong University of Science and Technology, Wuhan. 2002.

16. Zhang SF, Liu PSY, Zhai RH. An extended GRA method for MCDM with interval-valued triangular fuzzy Assessments and unknown weights. Computers \& Industrial Engineering. 2011; 61: 1336-41. DOI: 10.1016/j.cie.2011.08.008

17. Wang YM. Centroid defuzzification and the maximizing set and minimizing set ranking based on alpha level sets. Computers \& Industrial Engineering. 2009; 57(1): 228-36. DOI: 10.1016/j.cie.2008.11.014

\section{REFERENCES}

1. Chiarelli F, Marcovecchio ML. The molecular mechanisms underlying diabetic complications. Int J Pediatr Endocrinol. 2013; 2013(Suppl 1): 01. PMID: 24625012 DOI: 10.1186/1687-9856-2013-S1-01 [PubMed]

2. Type 2 diabetes guide [Internet]. 2012 [cited 2014 May 11]. Available from: http://www.webMD.com/

3. Type 2 diabetes [Internet]. 2010 [updated 2017 May 08; cited 2014 May 11]. Available from: http://www.nhs.uk/Conditions/Diabetes-type2 
Table 16: Decision matrix between alternatives based on criterions with interval-valued fuzzy numbers in GRA algorithm

\begin{tabular}{|c|c|c|c|c|c|}
\hline ن & 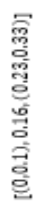 & $\begin{array}{l}\text { శ్ } \\
0 \\
0 \\
0 \\
0 \\
0 \\
0 \\
0 \\
0 \\
0 \\
0 \\
0 \\
0 \\
0\end{array}$ & 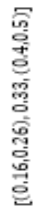 & 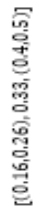 & 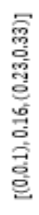 \\
\hline ن & $\begin{array}{l}\sigma \\
0 \\
0 \\
0 \\
0 \\
0 \\
0 \\
0 \\
0 \\
0 \\
0 \\
0 \\
0 \\
0 \\
0 \\
0\end{array}$ & 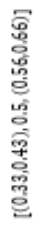 & 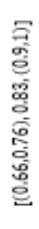 & $\begin{array}{l}\overline{6} \\
0 \\
0 \\
0 \\
0 \\
0 \\
0 \\
0 \\
0 \\
0 \\
0 \\
0 \\
0 \\
0 \\
0\end{array}$ & $\begin{array}{l}\text { 을 } \\
0 \\
0 \\
0 \\
0 \\
0 \\
0 \\
0 \\
0 \\
0 \\
0 \\
0 \\
0 \\
0 \\
0\end{array}$ \\
\hline ن & $\begin{array}{l}\sqrt{2} \\
0 \\
0 \\
0 \\
0 \\
0 \\
0 \\
0 \\
0 \\
0 \\
0 \\
0 \\
0 \\
0 \\
0\end{array}$ & $\begin{array}{l}\vec{D} \\
0 \\
0 \\
0 \\
0 \\
0 \\
0 \\
0 \\
0 \\
0 \\
0 \\
0 \\
0 \\
0 \\
0 \\
0\end{array}$ & $\begin{array}{l}\text { 이 } \\
0 \\
0 \\
0 \\
0 \\
0 \\
0 \\
0 \\
0 \\
0 \\
0 \\
0 \\
0 \\
0 \\
0\end{array}$ & $\begin{array}{l}\bar{\sigma} \\
0 \\
0 \\
0 \\
0 \\
0 \\
0 \\
0 \\
0 \\
0 \\
0 \\
0 \\
0 \\
0 \\
0\end{array}$ & $\begin{array}{l}\overline{2} \\
0 \\
0 \\
0 \\
0 \\
0 \\
0 \\
0 \\
0 \\
0 \\
0 \\
0 \\
0 \\
0 \\
0\end{array}$ \\
\hline نீ & 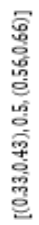 & 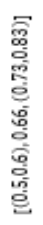 & 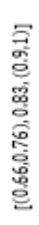 & $\begin{array}{l}\text { : } \\
0 \\
0 \\
0 \\
0 \\
0 \\
0 \\
0 \\
0 \\
0 \\
0 \\
0 \\
0 \\
0 \\
0\end{array}$ & $\begin{array}{l}5 \\
0 \\
0 \\
0 \\
0 \\
0 \\
0 \\
0 \\
0 \\
0 \\
0 \\
0 \\
0 \\
0 \\
0 \\
0\end{array}$ \\
\hline$\vec{U}$ & $\begin{array}{l}\text {. } \\
0 \\
0 \\
0 \\
0 \\
0 \\
0 \\
0 \\
0 \\
0 \\
0 \\
0 \\
0 \\
0 \\
0\end{array}$ & 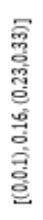 & 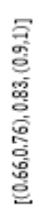 & 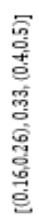 & 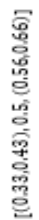 \\
\hline రె & $\begin{array}{l}\overline{3} \\
0 \\
0 \\
0 \\
0 \\
0 \\
0 \\
0 \\
0 \\
0 \\
0 \\
0 \\
0 \\
0 \\
0\end{array}$ & 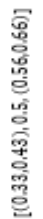 & 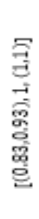 & $\begin{array}{l}2 \\
0 \\
0 \\
0 \\
0 \\
0 \\
0 \\
0 \\
0 \\
0 \\
0 \\
0 \\
0 \\
0 \\
0 \\
0\end{array}$ & $\begin{array}{l}7 \\
2 \\
0 \\
0 \\
0 \\
0 \\
0 \\
0 \\
0 \\
0 \\
0 \\
0 \\
0 \\
0 \\
0 \\
0\end{array}$ \\
\hline$\tilde{J}$ & $\begin{array}{l}\sigma \\
0 \\
0 \\
0 \\
0 \\
0 \\
0 \\
0 \\
0 \\
0 \\
0 \\
0 \\
0 \\
0 \\
0\end{array}$ & 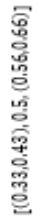 & 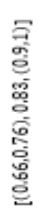 & $\begin{array}{l}\text { ᄅ. } \\
\infty \\
0 \\
0 \\
0 \\
0 \\
0 \\
0 \\
0 \\
0 \\
0 \\
0 \\
0 \\
0 \\
0\end{array}$ & $\begin{array}{l}\text { ㄱ. } \\
0 \\
0 \\
0 \\
0 \\
0 \\
0 \\
0 \\
0 \\
0 \\
0 \\
0 \\
0 \\
0\end{array}$ \\
\hline$\vec{J}$ & 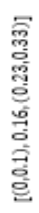 & 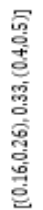 & 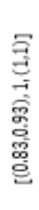 & 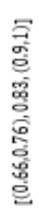 & 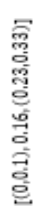 \\
\hline & $\vec{z}_{4}$ & 군 & $\frac{\pi}{4}$ & 云 & 过 \\
\hline
\end{tabular}

Table 17: Normalized decision matrix between alternatives based on criterions with interval-valued fuzzy numbers in GRA algorithm

\begin{tabular}{|c|c|c|c|c|c|}
\hline ن & 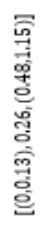 & 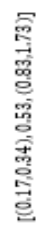 & 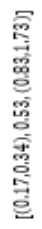 & 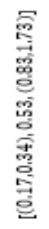 & 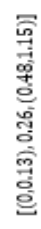 \\
\hline$E$ & 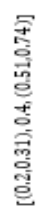 & 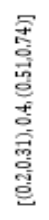 & 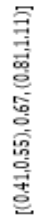 & 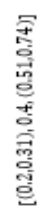 & 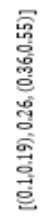 \\
\hline ن & 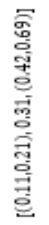 & 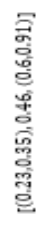 & 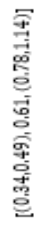 & 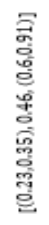 & 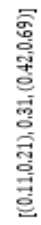 \\
\hline ن & 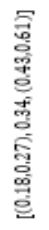 & 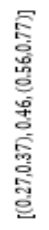 & 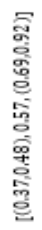 & 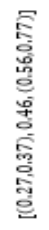 & 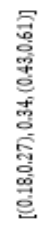 \\
\hline$\vec{U}$ & 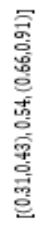 & 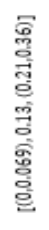 & 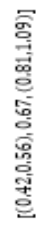 & 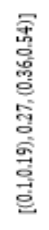 & 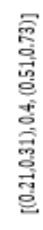 \\
\hline 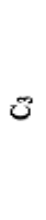 & 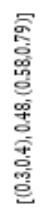 & 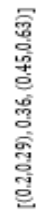 & 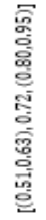 & 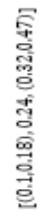 & 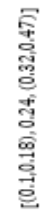 \\
\hline $\mathcal{J}$ & 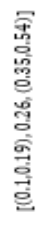 & 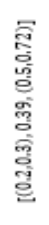 & 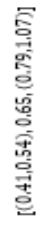 & 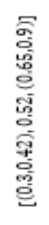 & 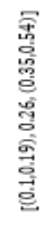 \\
\hline $\overrightarrow{0}$ & 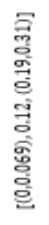 & 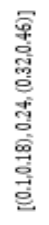 & 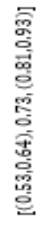 & 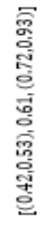 & 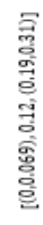 \\
\hline & $\overrightarrow{4}$ & दे & 安 & 云 & 先 \\
\hline
\end{tabular}


Table 18: The distance from the reference series in GRA algorithm

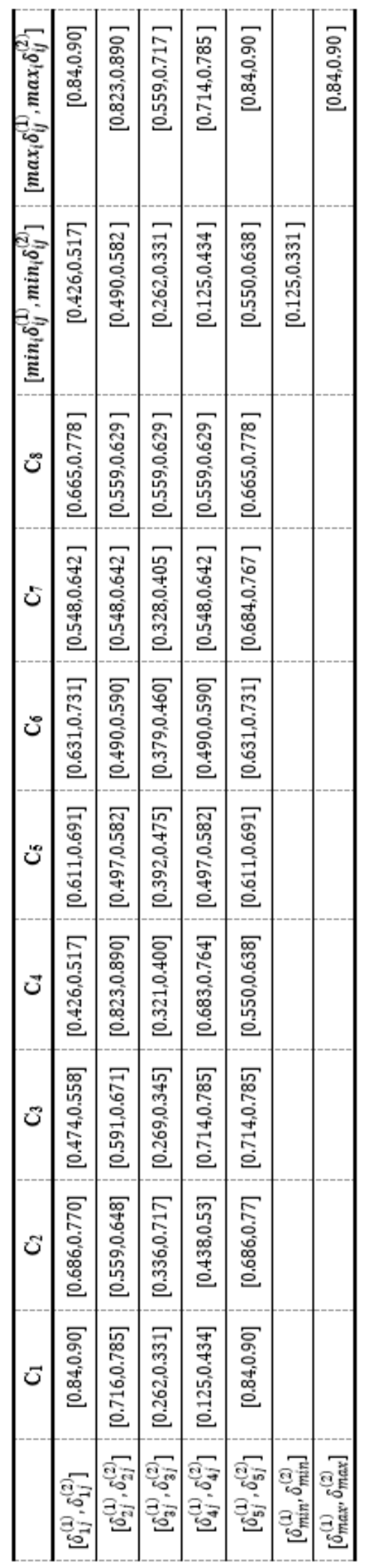

Table 19: The grey relational coefficient matrix $\left(\xi_{i j}^{(1)}\right)_{5 \times 8}$ in GRA algorithm

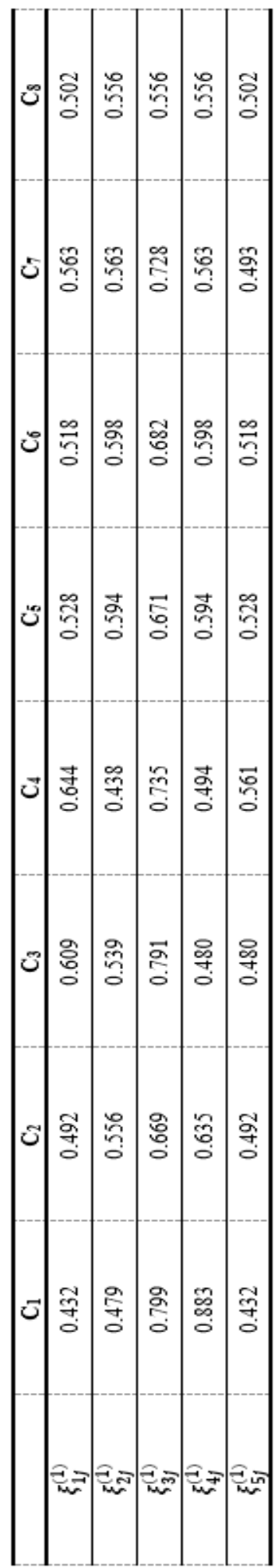


Table 20: The grey relational coefficient matrix $\left(\xi_{i j}^{(2)}\right)_{5 \times 8}$ in GRA algorithm

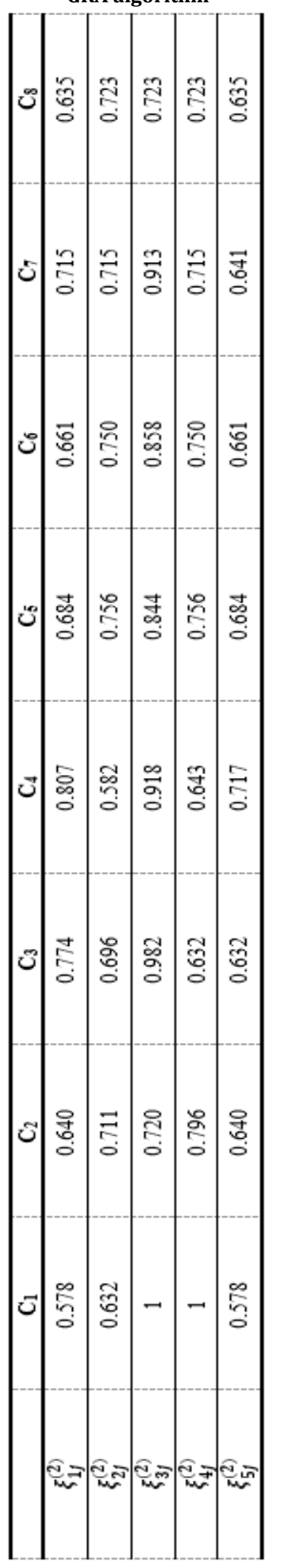

Table 21: The grey relational grade between the reference series and comparison series with triangular fuzzy values

\begin{tabular}{lrr}
\hline & $\gamma_{i}^{(\mathbf{1})}$ & \multicolumn{1}{c}{$\gamma_{i}^{(2)}$} \\
\hline $\mathrm{A}_{1}$ & $(0.3313,0.5451,0.8948)$ & $(0.4249,0.6998,1.15)$ \\
& & $(0.4131,0.6807$, \\
\hline $\mathrm{A}_{2}$ & $(0.3191,0.5268,0.8673)$ & $1.1214)$ \\
& & $(0.5331,0.8794,1.449)$ \\
\hline $\mathrm{A}_{3}$ & $(0.4531,0.7477,1.2327)$ & \\
& & $(0.4359,0.7211,1.196)$ \\
\hline $\mathrm{A}_{4}$ & $(0.3649,0.607,1.0108)$ & \\
& & $1.0499)$ \\
\hline $\mathrm{A}_{5}$ & $(0.2956,0.4868,0.8035)$ & \\
& &
\end{tabular}

